\title{
A assistência social prevista na Constituição de 1988 e operacionalizada pela PNAS e pelo SUAS
}

\author{
Potyara Amazoneida Pereira Pereira*
}

Resumo: Este artigo trata das transformações sofridas pela Assistência Social brasileira no curso da história, particularmente após a sua pioneira inserção na vigente Constituição da República Federativa do Brasil, promulgada em 1988. Seu foco central é a Política Nacional de Assistência (PNAS), de 2004, e o Sistema Único de Assistência Social (SUAS) que, a partir daquele ano, inauguraram um novo aparato normativo e institucional para essa área à semelhança do que já vinha sendo adotado na da Saúde. $\mathrm{O}$ artigo descreve e analisa os aspectos principais desse novo aparato para, ao final, tecer considerações críticas sobre a sua conveniência teórico-conceitual e possibilidades políticas.

Palavras-chave: seguridade social, Política Nacional de Assistência Social, sistema e processo.

The social assistance predicted by the Federal Constitution of 1988 and operationalyzed by the PNAS and by the SUAS

Abstract: This article is about the historical changes of the Brazilian Social Assistance particularly after its pioneering insertion

Professora titular do Departamento de Serviço Social (SER) do Instituto de Ciências Humanas (IH) da Universidade de Brasília UnB); coordenadora do Programa de Pós-Graduação em Política Social do SER/IH/UnB e coordenadora do Núcleo de Estudos e Pesquisas em Política Social (Neppos), do Centro de Estudos Avançados Multidisciplinares (Ceam) da UnB. 
in the existing Brazilian Federal Constitution, promulgated in 1988. Its central focus is in the National Social Assistance Policy (PNAS), of 2004, and in the Unified Social Assistance System (SUAS) that, from that referred year, inaugurated a new normative and institutional social assistance apparatus similar to the one that was already being adopted in the Health area. The article describes and analyzes the main aspects of this new apparatus in order to build critical considerations about its theoretical and conceptual conveniences and also its political possibilities.

Keywords: Social Security, National Social Assistance Policy, system and process.

\section{Transformação histórica da assistência social}

Para falar da Política Nacional de Assistência Social (PNAS) e do Sistema Único de Assistência Social (SUAS), aprovados em 2004, é preciso traçar o perfil das conquistas democráticas nessa área, pois são essas conquistas que estão na base da atual configuração legal, política e institucional da assistência social brasileira como política pública.

Com efeito, até 1988, a assistência social no Brasil não era considerada direito do cidadão e dever do Estado. Embora existisse desde o Brasil Colônia, a sua ação era ditada por valores e interesses que se confundiam com dever moral, vocação religiosa, sentimento de comiseração, ou, então, com práticas eleitoreiras, clientelistas e populistas. Nessa época predominava o que denominamos assistencialismo, isto é, o uso distorcido e perverso da assistência - ou a desassistência, como prefiro chamar -, porque a satisfação das necessidades básicas dos cidadãos não constituía o alvo dessas ações ditas assistenciais.

Portanto, só em 1988, com a promulgação da Constituição Federal vigente, a Assistência Social passou a ser considerada 
política pública de Seguridade Social, ao lado da Saúde e da Previdência, ganhando, então, um novo status e significado que não mais incorporava as antigas noções que a desfiguravam e a estigmatizavam.

Ao assumir a condição de política pública de Seguridade, que deveria concretizar direitos sociais previstos na Constituição, de 1988, e na Lei Orgânica da Assistência Social (LOAS), de 1993 - que regulamenta os artigos 203 e 204 da referida Carta Magna -, a assistência social deu, em verdade, um salto de qualidade. Não só saiu do crônico estágio de alternativa de direito, ou da abominável condição de anti-direito, mas revolucionou o pensamento juspolítico (jurídico e político). Exigiu também redefinições legais, teóricas e filosóficas, que lhe conferiram um paradigma próprio, antes inexistente, e contribuíram para a ampliação do catálogo de direitos no País.

Foi, pois, no âmbito das leis, dos conceitos, das idéias, e até das utopias, redefinidos a partir da crise do regime ditatorial (que vigorou no Brasil por 25 anos), que a assistência social brasileira lavrou tentos não desprezíveis: ganhou um paradigma norteador, centrado na cidadania; ressignificou-se, assumindo a identidade de política de Seguridade Social; e se introduziu nos ordenamentos jurídicos, nos currículos das universidades, na consciência e nos discursos de intelectuais e políticos formadores de opinião, nos debates parlamentares, na agenda dos governos e de organizações da sociedade civil. Transformou-se igualmente em objeto de estudos e pesquisas; em matéria suscitadora de polêmicas; em bandeira de luta de grupos simpatizantes (e até militantes) e em "espinha atravessada na garganta" de liberais e conservadores que, até hoje, não a reconhecem como direito devido. Enfim, contrariando previsões pessimistas e preconceitos arraigados, 
e remando contra a corrente neoliberal dominante, a assistência social vem, desde o início da década de 1990, constituindo-se, ironicamente, em importante espaço de construção de projetos sociais contra-hegemônicos.

Em suma, regida por lei federal (a LOAS), a assistência social passou a ser concebida como:

a) Política pública que, associada às demais políticas sociais e econômicas, deve concretizar direitos historicamente negados a uma ampla parcela da população. Como tal, ela passou a ter complexidade que requer conhecimento próprio, gestão qualificada e ação competente. Por isso, não deve ser encarada como mera distribuição de benefícios e serviços, mas como uma unidade de mecanismos diversos, interligados entre si, que vão desde a compreensão e o estudo da realidade, o planejamento, a definição de opções, a decisão coletiva (geralmente conflituosa), até a implementação, o acompanhamento e a avaliação das ações. $E$ isso exige aparato legal e institucional, recursos materiais e financeiros, além de pessoal qualificado a serviço do interesse público.

Por essa perspectiva, a Assistência Social não poderá:

- funcionar isolada das demais políticas públicas, porque nenhuma política é auto-suficiente. Por conseguinte, ela tem que estabelecer vínculos orgânicos com as suas congêneres, se não quiser desenvolver ações meramente paliativas;

- desenvolver ações focalizadas na pobreza extrema, porque está comprovado que tais ações produzem os seguintes efeitos perversos: a) valem-se da ausência de poder de pressão dos necessitados para oferecer-Ihes benefícios e serviços de baixa 
qualidade; b) funcionam como "armadilha da pobreza" porque não liberam os pobres de sua situação de privação; c) aumentam a pobreza porque, ao deixarem no desamparo grupos não focalizados, mas socialmente vulneráveis, contribuem para seu empobrecimento; d) estigmatizam a política e os seus destinatários, daí porque a política de assistência social deverá ter como referência o princípio da universalização, apesar de em si não ser universal.

b) Política de natureza incondicional, isto é, gratuita e desmercadorizável que, por não prever contrapartidas, constitui um dever de prestação dos poderes públicos e um direito de crédito do cidadão atendido - que é vítima histórica de uma enorme dívida social (Pisón, 1998). Tal concepção apóia-se na premissa de que, com o reconhecimento da assistência social como direito, a visão contratual de proteção social - que exige sempre contrapartida do beneficiário - é substituída por uma visão de proteção incondicional, baseada na cidadania, que dispensa qualquer tipo de contrapartida ou de condição.

c) Política cuja realização é de competência primaz do Estado, com o aval e o controle da sociedade. Essa primazia não se resume na garantia estatal dos direitos dos cidadãos, visto que só o Estado tem essa prerrogativa, mas também inclui: obrigações dos governos de prover bens e serviços sociais públicos; prontidão estatal para coibir abusos de poder e desrespeito às leis acatadas socialmente; remoção de obstáculos ao exercício da cidadania, dentre os quais a pobreza absoluta.

Tal concepção não implica - como muitos pensam paternalismo ou autoritarismo. Implica, sim, obrigar o Estado 
a arcar com responsabilidades que são suas e que lhe foram delegadas pela sociedade no curso do desenvolvimento da democracia. Portanto, está se falando de um Estado Social de Direito, e não de um Estado Liberal omisso, absenteísta e mercantilizador, que não encampa as causas sociais. Ou, mais precisamente, está se falando de um Estado que é fruto das lutas democráticas por maior liberdade e justiça social, o qual deverá ter como uma de suas principais funções a redução das incertezas sociais mediante políticas públicas. Trata-se, em resumo, de um Estado em ação, que, sob o controle ou pressão da sociedade, presta serviços ao mesmo tempo em que remove obstáculos à efetivação de direitos de cidadania conquistados coletivamente.

Tem-se assim, de forma breve, os traços definidores do paradigma da assistência social instituído em 1988, paradigma este que deveria ser levado em conta pelos governos pósditadura militar (Sarney, Collor, Itamar, Fernando Henrique e Lula), bem como pela sociedade, já que desta depende a sua legitimação.

Na qualidade de política pública, a Assistência Social ocupa um espaço institucional próprio: uma Secretaria Nacional de Assistência Social, do Ministério do Desenvolvimento Social e Combate à Fome, responsável pela elaboração da Política Nacional de Assistência Social (PNAS), de 2004. Na PNAS está previsto e definido, pela primeira vez na história da assistência, o Sistema Único de Assistência Social (SUAS), em atenção a uma recomendação da IV Conferência Nacional de Assistência Social, realizada em Brasília, em 2003.

A criação do SUAS obedeceu, portanto, a uma determinação da IV Conferência Nacional de Assistência Social que, por sua vez, "aprovou uma nova agenda política para o reordenamento das ações descentralizadas e participativas da 
assistência social no Brasil" (PNAS/2005), baseada no art. 6음 da LOAS que assim dispõe:

[...] as ações na área da assistência social são organizadas em sistema descentralizado e participativo, constituído pelas entidades e organizações de assistência social abrangidas por esta Lei, que articule meios, esforços e recursos, e por um conjunto de instâncias deliberativas compostas pelos diversos setores envolvidos na área - tendo como instância coordenadora o órgão gestor do governo federal.

Donde se conclui que o SUAS é, nos termos da lei, um mecanismo organizador dos preceitos, disposições, ações e procedimentos previstos na LOAS e na PNAS. Seu objetivo é o de garantir, do ponto de vista operacional e em caráter sistêmico (funcionalmente interligados), a implementação e gestão da Política. Ou seja, é por meio do SUAS que se irá saber: como os serviços, benefícios, programas e projetos previstos na LOAS e na Política vão ser organizados e oferecidos; onde podem ser encontrados; que pessoas ou grupos sociais terão acesso a eles e sob quais critérios; que padrões de atendimento vão ser definidos; como serão realizados, fornecidos e utilizados os estudos e diagnósticos que embasarão os atendimentos; e de que forma será feito o acompanhamento e a avaliação do próprio sistema e de seus resultados e impactos.

Contudo, por fazer parte da nova Política Nacional de Assistência Social, a compreensão do SUAS exige que, antes, se conheça a política nacional à qual está associado.

\section{A PNAS e o SUAS de 2004}

Quanto à nova política, convém esclarecer que ela apresenta várias mudanças em relação à PNAS anterior, datada de 1998, e, por isso, exigiu uma nova Norma Operacional 
Básica, conhecida como NOB/SUAS, criada em 2005, em substituição às NOBs de 1997 e 1998. Dentre as mudanças surgidas, merecem destaque a:

- definição da Assistência Social como política de proteção social;

- delimitação das proteções que ela deve assegurar;

- territorialização da ação;

- instituição do Sistema Único de Assistência Social (SUAS);

- novas bases de financiamento (Ipea, 2005).

Embora não esteja claro porque a PNAS/2004 preferiu chamar a política de assistência de política de proteção, em vez de seguridade - já que é como seguridade que foi concebida na Constituição Federal - o fato é que, como "proteção", a Assistência Social irá encarregar-se de "prover a proteção à vida, reduzir danos, monitorar populações em risco e prevenir a incidência de agravos à vida em face das situações de vulnerabilidade" (Brasil. MDS, 2005).

É, portanto, como ação protetora que a Assistência Social deve propiciar três principais tipos de segurança: de sobrevivência, de acolhida e de convívio.

A segurança de sobrevivência consiste, basicamente, na prestação governamental de um valor monetário mínimo aos idosos e às pessoas com deficiência pobres - não contribuintes da Previdência Social e sem condições de se manter ou ser mantidos por suas famílias - bem como às vítimas de calamidades ou de outras contingências sociais. Esta segurança será viabilizada por meio da distribuição do Benefício de Prestação Continuada (BPC), no valor de um salário mínimo, e dos Benefícios Eventuais (em fase de 
regulamentação), assim como de bolsas-auxílios financeiros condicionais e passíveis de serem objeto de contratos de compromissos.

A segurança de acolhida refere-se ao atendimento de demandantes especiais da Assistência Social em espaços físicos e por serviços estrategicamente montados em todo território nacional para prestarem provisões básicas, especialmente as que se referem à alimentação, ao vestuário e à moradia. Dentre esses demandantes, incluem-se pessoas com histórias de abandono, violência familiar ou social, velhice e deficiência desprotegida, consumo de drogas, entre outras. Para se viabilizar, esta segurança requer a oferta de uma rede de serviços e de locais de permanência de curta, média e longa duração - sob a forma de abrigos, albergues, alojamentos, vagas -, dotados de condições físicas e profissionais que garantam: a escuta profissional qualificada, a informação devida, a provisão requerida e ações socioeducativas.

Por fim, a segurança de convívio diz respeito à construção, restauração e fortalecimento dos laços familiares e comunitários de demandantes da assistência com fracos vínculos afetivos e sociais. Tal segurança requer, igualmente, oferta pública de atividades socioeducativas, culturais e de convivência em espaços definidos.

Esses três tipos de segurança visam ao desenvolvimento humano e social associado à cidadania, e regem-se pelos seguintes princípios: centralidade familiar, territorialização, proteção pró-ativa, integração à seguridade sociale integração às políticas sociais e econômicas.

A centralidade familiar está associada ao fato de a família ser considerada na PNAS/2004 o espaço insubstituível de 
proteção e socialização primárias dos indivíduos. Portanto, a família constitui o núcleo básico e matricial das seguranças assistenciais previstas na referida PNAS. Mas, para que a família assuma as responsabilidades que lhe são reservadas, tornase preciso que ela seja redefinida, isto é, entendida como um conjunto de pessoas que se acham unidas não só por vínculos consangüíneos, mas por laços afetivos e de cooperação. Esse entendimento supera referências de tempo e lugar para a localização da família, rompendo, simultaneamente, com a prática da política social que considera o grupo familiar como unidade econômica ou referência de cálculo de rendimento per capita para a concessão de benefícios. Além disso, a família como unidade de proteção primária também precisa de proteção pública, o que a coloca na condição de sujeito de direitos sociais e não só de deveres.

Pelo fato de os núcleos familiares estarem distribuídos por todo o território nacional, suas necessidades requerem respostas político-administrativas descentralizadas. Essa descentralização - que constitui um princípio gêmeo da participação - está na base da democratização da política de Assistência Social. Todavia, diferentemente do que preconiza a LOAS, a PNAS/2004 concebe um caminho descentralizador que não se restringe à distribuição de poderes, responsabilidades e encargos entre os três entes federados: União, Estados e municípios, incluindo-se, nesse conjunto, o Distrito Federal como um misto de Estado e município.

A descentralização prevista pela nova PNAS pauta-se pelo conceito de territorialização que, no estabelecimento de prioridades sociais, leva em conta recortes territoriais que contenham populações com problemas, culturas e histórias similares. Assim, em vez de privilegiar demarcações geográficas tradicionais, a Política privilegia a delimitação de espaços ou regiões homogêneos como pré-requisito às ações integradas 
e intersetoriais. Por isso, a ênfase não será dada ao espaço físico formal como possível definidor da descentralização da Política, mas a agrupamentos e áreas homogêneos. Isso requer um redesenho da rede socioassistencial, pois os municípios que constituem as unidades básicas da Política deverão ser caracterizados de acordo com o seu porte demográfico. Assim, quanto mais populoso for um município, maior será a necessidade de desagregá-lo territorialmente em grupos homogêneos, tendo como parâmetro diferenças e desigualdades existentes no seu interior. Da mesma forma, em municípios de pequeno porte, o agrupamento de áreas homogêneas poderá ultrapassar o espaço municipal e ir compor regiões integradas ou consórcios intermunicipais. Estes são os procedimentos e regras baseados no princípio da territorialização.

O princípio da proteção pró-ativa prevê a prontidão dos poderes públicos em desenvolver ações voltadas para a redução de ocorrências de riscos e danos sociais, o que confere à Política caráter simultaneamente preventivo e corretivo.

$\mathrm{E}$, finalmente, os princípios da integração às políticas de Seguridade Social e às demais políticas sociais e econômicas reafirmam o que já está contido na LOAS: manter a política de Assistência Social inserida no conjunto da Seguridade Social, em articulação com a Saúde e a Previdência, mas sem perder de vista a sua indispensável relação de mútua implicação com as outras políticas públicas - sociais e econômicas - não integrantes do compósito da Seguridade Social brasileira, demarcado na Constituição.

Esse conjunto de seguranças, guiadas por seus respectivos princípios, será aplicado de acordo com a seguinte divisão da proteção social no campo da Assistência: básica e especial. 
A proteção social básica tem caráter mais preventivo, enquanto, a especial, caráter mais reparador. Assim, a primeira visa prevenir situações de riscos sociais por meio do desenvolvimento de potencialidades e possibilidades de melhoria de condições de vida e de cidadania, assim como do fortalecimento dos vínculos familiares e comunitários. Já a segunda visa atuar nas situações de riscos já instalados, caracterizados, predominantemente, pela pobreza absoluta, pelo acesso precário ou ausente aos serviços sociais públicos, pela fragilidade ou ausência de vínculos afetivos e de pertencimento social, e pela presença permanente de discriminações relacionadas à idade e à deficiência.

Tendo como referência a família e a territorialização, a proteção social básica reúne serviços, programas, projetos e distribuição de benefícios locais, abarcando as seguranças de subsistência, de acolhida e de convívio. Em vista disso, o Benefício de Prestação Continuada (BPC) e os Benefícios Eventuais integram essa categoria de proteção ao lado das ações de acolhimento e convívio, já mencionadas, que devem manter articulação com os demais programas e serviços prestados pelas três esferas de governo.

A coordenação e execução dos serviços de proteção social básica ficam a cargo dos Centros de Referência da Assistência Social (CRAS), ou Casas da Família, localizados em áreas territoriais com vulnerabilidades sociais homogêneas ou similares, tendo sob sua responsabilidade até 1.000 famílias/ ano em cada território de 5.000 famílias. Além dos serviços de proteção básica, os CRAS têm como incumbência:

mapear, organizar e coordenar a rede de serviços socioassistenciais local; inserir as famílias nestes serviços; prestar informação e orientação para a população em sua área de atuação; e manter 
um serviço de 'vigilância da exclusão social', produzindo, sistematizando e divulgando indicadores sociais (Ipea, 2005, p. 48).

São exemplos de serviços de proteção social básica:

- Programa de Atenção Integral às Famílias (Paif);

- programas de inclusão produtiva e projetos de enfrentamento da pobreza;

- centros de convivência para idosos;

- serviços para crianças de até 6 anos, que visem o fortalecimento do vínculo familiar, com ações que favoreçam a socialização, a valorização do brinquedo e a defesa dos direitos da criança;

- serviços socioeducativos para crianças e adolescentes na faixa de 6 a 14 anos, visando à sua proteção e socialização e ao fortalecimento dos vínculos familiares e comunitários;

- programas de incentivo ao protagonismo juvenil, com fortalecimento dos vínculos familiares e comunitários;

- centros de informação e de educação para o trabalho para jovens e adultos.

Centrada nas situações de risco já instalado, a proteção especial tem como público-alvo crianças, adolescentes, jovens, adultos, pessoas com deficiência, idosos e migrantes, atingidos por processos de abandono, maus tratos físicos ou psíquicos, abuso sexual, uso de substâncias psicoativas, cumprimento de medidas socioeducativas, situação de rua, situação de trabalho infantil - processos esses que se tornam mais agudos no cotidiano da pobreza e do desemprego. 
Para enfrentar essas situações de necessidades acumuladas e aprofundadas, os serviços de proteção social especial dividem-se em duas categorias: de média e alta complexidade.

Os de média complexidade têm como objeto casos de direitos violados e de marginalidade cujos sujeitos ainda mantêm vínculos familiares e comunitários preservados. Nesse caso, as ações desenvolvidas prevêem uma estrutura de atenção especializada e/ou acompanhamento sistemático e monitorado, como, por exemplo, abordagens de rua, prestações de cuidados no domicílio e medidas socioeducativas em meio aberto. E os de alta complexidade têm como alvo pessoas sem referência familiar e comunitária, necessitando de apoio institucional integral, mediante o qual devem ser providos moradia, alimentação, higienização e trabalho protegido.

As escalas de complexidade dos serviços não estão referidas apenas aos desafios colocados pela maior ou menor magnitude dos riscos sociais a serem enfrentados pela política, mas também estão relacionadas com o tamanho do município e com a sua densidade populacional. Assim, se em municípios pequenos, com uma população de até 50.000 habitantes, a instalação de uma rede de proteção básica (unindo população e território a serviços organizados de maneira uniforme e próxima do cidadão) é considerada simples, o mesmo não ocorrerá nos municípios de grande porte. Nestes, haverá necessidade de se implantar uma rede mais ampla de serviços de complexidade média e alta.

É nesse contexto e dentro dessa lógica que o SUAS deve funcionar, não como algo além ou acima da Política, mas como um de seus instrumento, isto é, como um modelo da gestão unificada da Política em todo o Brasil, tendo como principal 
função organizar as três esferas de governo em torno da gestão compartilhada, da divisão pactuada de competências e do seu efetivo co-financiamento (Ipea, 2005). Ou seja, o SUAS é um instrumento de gestão da Política de Assistência e, como tal, deve organizá-la, estabelecer um padrão comum de serviços e implantar uma sistemática de acompanhamento e avaliação, contando com efetivo financiamento. Portanto, tudo o que está previsto na PNAS/2004, em termos de proteção, segurança, princípio, avaliação e financiamento, deverá estar contido no SUAS de forma sistêmica e operacionalizável, de acordo com as especificações da NOB/2005.

Como suporte financeiro do SUAS, a PNAS/2004 prevê ainda uma nova sistemática de financiamento da assistência social, também em atenção às recomendações da IV Conferência. Nessa sistemática, os antigos convênios firmados entre as esferas de governo para financiar serviços, programas e projetos assistenciais foram substituídos por repasses automáticos fundo a fundo. O mecanismo de convênio permanecerá apenas para apoiar financeiramente projetos e programas não continuados, reforçando assim os fundos especiais de assistência como instâncias privilegiadas de financiamento em cada unidade da Federação. Isso quer dizer que a gestão financeira descentralizada da Assistência Social se efetivará através desses fundos, "utilizando critérios de partilha de todos os recursos neles alocados, os quais são aprovados pelos respectivos Conselhos de Assistência Social" (Brasil. MDS, 2005, p. 52). Além disso, a nova sistemática de financiamento estabelece a fixação de pisos de atenção básica e especial, tendo em vista as suas complexidades, substituindo, assim, os antigos valores per capita baseados no número de atendimentos. 
Todas essas disposições, conteúdos e definições, contidos na PNAS/2004 e sistematizados no SUAS, estão detalhados e regulamentados pela NOB/2005, conhecida como NOB/SUAS, que disciplina a operacionalização da atual Política de Assistência Social, substituindo as antigas NOBs, criadas em 1997 e 1998, e que, basicamente, disciplina:

- a divisão de competências e responsabilidades entre as três esferas de governo;

- os níveis de gestão de cada uma dessas esferas;

- as instâncias que compõem o processo de gestão e de controle dessa política e como elas se relacionam;

- a nova relação com as entidades e organizações governamentais e não-governamentais;

- os principais instrumentos de gestão a serem utilizados; e

- a forma de gestão financeira, que considera os mecanismos de transferência e os critérios de partilha e de transferência de recursos (Brasil. MDS, 2005, p. 14).

\section{Considerações críticas sobre a PNAS e o SUAS/2004}

Em que pesem as mudanças contidas na PNAS/2004, que, na verdade, vinham sendo gestadas desde anos anteriores, o SUAS ainda está se implantando e sendo objeto de avaliações críticas. Uma dessas avaliações diz respeito ao fato de ele ser uma reprodução do Sistema Único de Saúde (SUS) e, portanto, um instrumento que não teve como referência mestra as particularidades teóricas e políticas da área de assistência social. Em vista disso, pergunta-se: como uma política setorial e universal como a de Saúde, que 
obedece a protocolos internacionais gerais, poderá servir de espelho fiel para uma política intersetorial e particularista como a de Assistência, que não possui protocolos internacionais e cujos avanços teóricos, democráticos e cívicos restringem-se particularmente ao Brasil? Como justificar, na Assistência, a incorporação de um sistema que, na Saúde, emprega termos ou conceitos especializados, cuja conotação difere ou se antagoniza com o sentido dos mesmos no âmbito da Assistência, a saber: na Saúde, a assistência não é uma ação promotora, mas cuidadora ou reparadora; na Saúde, o que promove é a atenção, e não a assistência; e, na Saúde, o termo coletivo é muito mais consistente e valorizado do que o termo público que, na Assistência, é mais do que coletivo: é sinônimo de universalização.

Por outro lado, as complexidades da atenção à Saúde (baixa, média e alta) foram estabelecidas com base em patologias codificadas internacionalmente com seus respectivos tratamentos. A política de Assistência não trabalha - ou não deveria trabalhar -, com o conceito de patologia e nem deveria identificar demandas e necessidades sociais de seus destinatários com este conceito. Tal identificação, por mais sutil que seja, recupera uma concepção equivocada, de corte funcional, das mudanças sociais. Além do mais, no âmbito do trabalho da Assistência Social, é difícil dizer o que é ou não é mais e menos complexo. Nesse âmbito, uma ação preventiva pode ser muito mais complexa e onerosa do que uma ação corretiva. A dinâmica social não comporta categorizações rígidas.

Esses e outros exemplos têm incomodado muitos analistas do Sistema Único de Assistência Social, dentre os quais me incluo. Muitos outros incômodos poderiam ser listados, mas, para os fins deste artigo, importa salientar o uso do termo "vigilância da exclusão", como uma espécie de réplica 
de "vigilância sanitária" empregado na Saúde. A questão é que, no âmbito da Saúde, a vigilância sanitária tem poder de polícia. Em vista disso, pergunto: qual a relação que a vigilância da exclusão tem com o controle democrático, previsto na LOAS e no pensamento acumulado referente à Assistência como política pública concretizadora de direitos? Essa vigilância teria, no âmbito da política de Assistência Social, o poder de polícia que a vigilância sanitária possui de apreensão de alimentos, de interdição de casas comerciais e da emissão de voz de prisão em casos de atentado à saúde da coletividade? Se tivesse, como ficaria o Ministério Público, que, na Constituição Federal e na LOAS, é considerado parte legítima na defesa dos direitos sociais e individuais indisponíveis? Por que não usar, na Assistência, o conceito de controle democrático, ou controle público, em vez de controle social como faz o SUS, já que o controle a que Assistência se refere emana das bases da sociedade e não do Estado como, na acepção clássica, o termo controle social era empregado? Por que qualificar a política de Assistência Social como política de proteção e não de seguridade ou mesmo política social, que têm conotações mais densas, consistentes e precisas?

Além disso, embora reconhecendo a importância de uma organização explícita e articulada da Política de Assistência Social, pergunto se essa organização deveria ser chamada de sistema, já que toda política pública é um processo que pode ser planejado e acompanhado em sua movimentação. Das leituras dos documentos oficiais e das tendências em voga, o que se depreende é que não é a Política que contém o Sistema, mas é este que a contém.

Em adição, pergunto se a NOB-SUAS, que também foi inspirada na Saúde, não poderia fazer a vez do SUAS, já que é ela que contempla o Sistema e o detalha. A impressão que fica da análise do conjunto PNAS-NOB-SUAS é que 
o campo da Assistência Social está sendo cada vez mais enquadrado em padrões, modelos e submodelos de gestão que superestimam a racionalidade técnica, que, por sua vez, escalona hierarquicamente o conteúdo da Política em várias partes que se repetem com pequenos acréscimos. Em relação a isso, falava-se, em 2006, na elaboração de um Plano Nacional de Assistência Social, ao que, naquela época, eu me indagava: em que esse plano diferiria da PNAS? A Política já não contém em si o Plano? Os atuais planos estaduais, municipais e distrital da Assistência Social não traduzem as políticas desses entes federados? Qual a concepção de política de ação para o SUAS?

Por outro lado, grande parte dos programas de assistência social ainda não apresenta importantes alterações e significativos resultados em nome do SUAS. Em comparação com anos anteriores, a maioria deles apresenta situação quase estável. Entretanto, alguns desses programas, sob a responsabilidade do governo federal, merecem destaque pelo seu crescimento e ampliação de cobertura que nem sempre se devem ao SUAS.

O principal deles foi o BPC que, em 2004, teve grande incremento na sua cobertura graças à introdução de novas regras na legislação desse benefício com a entrada em vigor do Estatuto do Idoso naquele ano. Assim, para atender à determinação do referido Estatuto de que a idade mínima para a solicitação do BPC é de 65 anos, houve a redução da idade de 67 anos, prevista nas Normas da Assistência Social, para 65. Além disso, em relação aos idosos, a antiga e polêmica restrição do benefício a uma pessoa por residência - já que seu valor monetário entrava no cálculo da renda familiar definida como até $1 / 4$ do salário mínimo - foi extinta. Hoje, mais de uma 
pessoa idosa credenciada para receber o benefício poderão ser atendidas em uma mesma residência, o que impôs outra mudança na política do BPC: a família deixou de ser a base de cálculo para a concessão de benefícios aos idosos. E outras mudanças poderão acontecer no âmbito do BPC em curto prazo, quando for aprovado o Estatuto da Pessoa com Deficiência.

Por esses fatos chega-se à conclusão de que o SUAS corre paralelamente a várias ingerências no campo da Assistência Social, muitas delas com cara de assistencialismo e que escapam do controle do Sistema. Isso, sem falar nos desafios que esse Sistema tem de enfrentar, a começar pela construção de uma identidade que se paute pelas particularidades da assistência como política com conteúdo próprio. Sem essa construção, a sua operacionalização sistêmica ficará presa a uma racionalidade instrumental, que é estranha à dinâmica de uma sociedade em mutação, e se chocará com princípios e critérios baseados em concepções, como as da Saúde, que não são as contempladas no paradigma que reconceituou a Assistência Social nos marcos da Constituição Federal de 1988.

\section{Referências bibliográficas}

BRASIL. Constituição Federal de 1988. Brasília: Câmara dos Deputados, Centro de Documentação e Informação, Coordenação de Publicações, 2002.

BRASIL. Lei Orgânica da Assistência Social. 3. ed. Brasília: MAS, 2003.

Brasil. MINISTÉRIO DO DESENVOLVIMENTO SOCIAL E COMBATE À FOME (MDS). Secretaria Nacional de Assistência Social. Política Nacional de Assistência Social - PNAS e Norma Operacional básica NOB/SUAS. Brasília, 2005. 
IPEA. Políticas sociais: acompanhamento e análise nำ10. Agosto de 2005.

PEREIRA-PEREIRA, Potyara A. política de Assistência Social no Brasil: avanços e retrocessos. In: CONFLITOS de interesses e a regulamentação da política de assistência social. Brasília: Neppos/ Ceam/UnB, 2002. (Cadernos do Ceam n. 11).

PISÓN, Jose Martinez. Políticas de bienestar: un estudio sobre los derechos sociales. Madrid: Tecnos, 1998. 